\title{
Paisagem Cultural Industrial: memórias de um patrimônio da contemporaneidade
}

\author{
Ronaldo André Rodrigues da Silva \\ Adm., Eng. Eletricista. Me., Administração, Master em Conservação e Restauração do Patrimônio Arquitetônico Urbano \\ [ETSAM/UCM-Espanha]. TICCIH-Brasil. Professor da Pontifícia Universidade Católica de Minas Gerais. Belo Horizonte \\ [MG], Brasil.<ronaldoandre@gmail.com>.
}

CONPADRE'2010. Apresentado no 1ํ Seminário de Patrimônio Industrial [Conpadre n.05/2010],

Conferência Internacional sobre Patrimônio e Desenvolvimento Regional. Campinas e Jaguariúna [Brasil], 2010.

\begin{abstract}
Resumo
O trabalho apresenta os conceitos de patrimônio industrial e patrimônio cultural a partir das relações estabelecidas entre a vida social e a vida econômica sob uma perspectiva da paisagem industrial e o desenvolvimento das paisagens organizacionais. A paisagem cultural é concebida a partir de uma visão integrada entre sociedade e empresa a partir de uma infinita rede de interconexões em que convergem os conceitos de patrimônio e cultura. As relações estabelecidas inserem aspectos da memória cultural e social e aproximam tais conceitos, garantindo-Ihes um caráter interdisciplinar com nuances cultural, social e econômica. Faz-se necessário destacar uma "específica" paisagem sócioindustrial que determina identidades próprias que possibilita conhecer uma região, um espaço geográfico e época vividas a partir de seu entorno e permite entender as transformações e reflexos das condições de vida e de trabalho dos indivíduos. Além disso, pode-se descrever fatores particulares de construção de memória, identidade e cultura para explicar questões sociais e expectativas e limitações de uma dada sociedade contemporânea. $O$ entrelaçamento dos conceitos de história, memória, cultura e organização é uma possibilidade de entendimento das relações e práticas do trabalho e sociedade, entremeadas por suas conseqüências sócio-econômicas e culturais. A ampliação do conceito patrimonial constitui-se em um desafio, pois permite desenvolver a memória e a história cultural-industrial e possibilita um maior entendimento da continuidade temporal entre passado-presente-futuro.
\end{abstract}

Palavras-chave

Paisagem Cultural, Patrimônio Cultural, Patrimônio Industrial.

\section{Industrial and cultural landscape: memories from a heritage of contemporaneousness}

\begin{abstract}
The paper presents the industrial heritage and cultural heritage concepts from the relationships established between the social and economic life from the perspective of the industrial landscape and the development of organizational landscapes. The cultural landscape is conceived from an integrated view of society and business from an endless web of interconnections that converge in the heritage and culture concepts. The relations established fall aspects of cultural and social memory and approach these concepts, providing them with an interdisciplinary characteristics. It is necessary to highlight a "specific" social-industrial landscape that determines its own identity and makes possible to know a region, a geographic space and time experienced from their surroundings and helps us understand the transformations and reflections of the conditions of life and work of individuals. Moreover, its describe factors particular of the construction of memory, identity and culture to explain social issues, expectations and limitations of a particular contemporary society. The intertwining of the history, memory and culture concepts and organization is a possibility of understanding the work relationships and society, intertwined by the socio-economic and cultural consequences. Expanding the heritage concept asset constitutes a challenge, because it allows developing memory and the
\end{abstract}


cultural-industrial history and provides a greater understanding of the temporal continuity between past-present-future.

\section{Keywords}

Cultural Landscape, Cultural Heritage, Industrial Heritage.

\section{Patrimônio Cultural e Patrimônio Industrial}

O conceito de patrimônio cultural tem sido recentemente ampliado ao qual se tem agregado agregado ao tradicional a patrimonialidade material e se tem pensado a natureza e a diversidade como fatores preponderantes ao seu conteúdo. Tais fatores determinam, nos últimos anos, uma ampliação que engloba as ciências humanas, já tradicionalmente inscritas em suas definições, mas também as exatas (patrimônio tecnológico e material) e as da saúde e biológicas (patrimônio genético). Além das novas formas de 'pensar' o patrimônio emergem também com maior intensidade 0 patrimônio imaterial e o patrimônio intangível (ABREU e CHAGAS, 2003).

Para Castriota (2009b), a ampliação do conceito leva a uma desconstrução e reconstrução dos parâmetros até então utilizados, pois são necessários novos olhares para o entendimento da abrangência. A necessidade de inclusão de aspectos que envolvam a identidade e identificação dos grupos sociais a que pertencem os elementos patrimoniais, torna-se necessário avaliar como a tradição, os costumes, as mudanças culturais interferem na percepção desse elementos e desenvolvem a memória e a história dos lugares a que pertencem, das comunidades que os delimitam e a sua identidade social.

As diferentes relações estabelecidas com o tempo e com o espaço determinam as mudanças nas percepções entre as tradições e sua importância para a construção das diversas identidades - individuais e coletivas. Os novos modelos patrimoniais e culturais redefinem essas identidades e levam à identificação de elementos que tendem a contribuir para uma nova relação entre passado-presente-futuro, entre memória-história e entre individuo-coletividade.

A inclusão de parâmetros 'novos' ao conceito de patrimônio tem procurado aproximar ainda mais os temas correlacionados à condição dos elementos considerados essenciais à memória e à história de lugares e grupos sociais. Algumas questões relacionadas à monumentalidade, à particularidade e à identidade têm sido redefinidas ou reconstruídas segundo o entendimento de diversos grupos envolvidos, direta e indiretamente, que se consideram responsáveis pela preservação e conservação de determinado patrimônio, mas principalmente por sua memória e identidade, seja individual ou coletiva. Com tais referencias reconstruídas, as oportunidades para se discutir e incluir o patrimônio industrial dentre aqueles considerados como patrimônios culturais tem permitido amplas discussões.

O conceito de patrimônio cultural, atualmente, construído pelo órgão nacional, o IPHAN (Instituto do Patrimônio Histórico e Artístico Nacional) privilegia, de certa 
maneira, a preservação do patrimônio industrial, mesmo que indiretamente. A Convenção para a Salvaguarda do Patrimônio Cultural Imaterial, de 17 de outubro de 2003, apresenta uma preocupação com o conhecimento transmitido de maneira geracional, promovido pelos diversos grupos sociais que promovem

[...] a interação entre ambiente, natureza e história, gerando um sentimento de identidade e continuidade, contribuindo assim para promover o respeito à diversidade cultural e à criatividade humana (IPHAN, 2003).

Exemplo desta preocupação constitui-se no tombamento do Ofício das Paneleiras de Goiabeiras, no Espírito Santo ou dos remanescentes da Real Fábrica de Ferro São João de Ipanema (Iperó, SP) que se apresentam quase que 'casos isolados' no que se refere à preservação do patrimônio industrial - material ou imaterial - no âmbito nacional.

A preocupação com o patrimônio imaterial e urbano atrelado ao patrimônio industrial pode igualmente ser observada em alguns casos que se apresentam a partir de iniciativas públicas ou privadas e tem permitido uma crescente preocupação com o patrimônio histórico e industrial, como por exemplo, iniciativas para tombamento e conservação de caixas d'água, fábricas têxteis, engenhos, instalações e complexos ferroviários, usinas hidrelétricas e siderúrgicas, dentre outros.

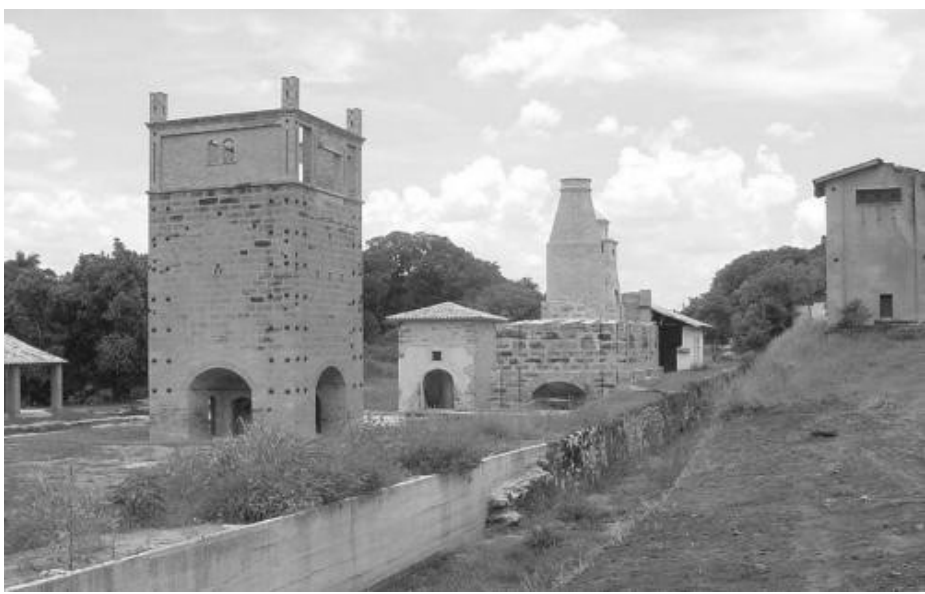

Figura 01. Real Fábrica de Ferro de Ipanema - Iperó [SP], Brasil. Fonte: Janete Gutierre, <http://www.ibama.gov.br/> [s/d].
Entretanto, as origens do conceito de patrimônio industrial remontam aos anos 50 do século $X X$, quando o termo arqueologia industrial foi popularizado por Michel Rix, apesar de suas origens se apresentarem ao final do século XIX. Dentre os precursores se tem o português Francisco de Sousa Viterbo que publicou o artigo "Arqueologia Industrial Portuguesa: Os Moinhos" (1986), sendo um dos primeiros a utilizar a expressão "arqueología industrial" e que fez dela uma nova disciplina para pesquisadores e educadores em relação aos restos e remanescentes do passado das atividades industriais, memórias das pessoas, das técnicas e da tecnologia. O primeiro livro e o primeiro periódico foram publicados por Kenneth Hudson em 1963, nos quais ainda cita-se a Mr. Donald Dudley, professor de latim da Universidade de Birgminham, que utilizava a expressão 'arqueologia industrial' em suas palestras. (HUDSON, 1965; TRINDER, 1992).

Antes dos anos 50 do século $X X$, as referências à expressão vinculavam-se à necessidade de identificação, preservação e conservação do patrimônio industrial britânico a partir das estruturas, artefatos y lugares que poderiam identificar o passado econômico e as atividades sociais a ele relacionadas. (MINCHINTON, 1983; PALMER \& NEAVERSON, 1998). O termo foi aceito somente na década de 60 do século XX como aquela área específica de estudos em que não havia uma 
preocupação centrada no patrimônio material, mas, também, nas reminiscências da sociedades, levando-se em consideração os parâmetros sociais e culturais que definiam a sociedade industrial.

Em 2003, através da Carta de Nizhny, o TICCIH (The Internation Committee for the Conservation of the Industrial Heritage) construiu conceitos de patrimônio industrial e arqueologia industrial os quais abarcavam o seguinte conteúdo:

[...] O patrimônio industrial se compõe dos restos da cultura industrial que possuam um valor histórico, tecnológico, social, arquitetônico ou científico. Estes restos consistem em edifícios e maquinaria, escritórios, moinhos e fábricas, minas e lugares para processar e refinar, armazéns e depósitos, lugares onde se gera, se transmite e se usa energia, meios de transporte e toda sua infra-estrutura, assim como os lugares onde se desenvolvem as atividades sociais relacionadas com a indústria, tais como as moradias, o culto religioso ou a educação.

A arqueologia industrial compreende um método interdisciplinar para o estudo de toda evidência, material ou imaterial, de documentos, artefatos, estratigrafia e estruturas, assentamentos humanos e terrenos naturais e urbanos, criados por processos industriais ou para eles. A arqueologia industrial faz uso dos métodos de pesquisa mais adequados para fazer entender melhor o passado e o presente industrial. (TICCIH, 2003).

A importância da arqueologia industrial surge, para López García (1992), a partir de um momento em que a sociedade pós-industrial, ou da informação, passa por mudanças que determinam novos paradigmas de estudo dominados pela automatização e pela importância central dada aos processos informacionais. Redefine-se uma nova era "neoindustrial" na qual é necessário ter presente o passado mais próximo para compreender melhor o futuro e conformar com isso a imagem e a pessoalidade do lugar em que se vive. A dimensionalidade temporal do patrimônio apresenta uma relação com o espaço e, portanto, com as idéias que poderiam ser estendidas às de paisagem cultural, conforme apresentado por Magalhães apud Gallo (2006, p.101).

[...] essa relação de tempo é curiosa porque é preciso entender o bem cultural num tempo multidimensional. A relação entre a anterioridade do passado, a vivência do momento e a projeção que se deve introduzir é uma coisa só. É necessário transitar o tempo todo nessas três faixas, porque o bem cultural não se mede pelo tempo ecológico... o tempo cultural não é cronológico. Coisas do passado podem, de repente, tornaram-se altamente significativas para o presente e estimulantes para o futuro (MAGALHÃES, 1997, p.75).

As diferentes maneiras de articulação existentes entre a cultura e a memória, a história e a sociedade, reescrevem um passado e presente, muitas vezes recente, mas esquecido. Além disso, definem novas maneiras de se enxergar as fronteiras e articulações que identificam uma linguagem nacional própria e uma identidade e memória sociais que muitas vezes são significantes e trazem significado a questões que inquietam estudiosos e apaixonados pela memória cultural. (FERREIRA e ORRICO, 2002)

Segundo Choay (2001), o patrimônio industrial possui características peculiares que Ihe garantem certa particularidade quando destacado em relação ao patrimônio cultural. A natureza e a escala diferenciadas determinam uma maneira única ao se 
tratar sua definição e também sua identificação e identidade. A mera classificação de edifícios ou de aspectos arquitetônicos não permite abarcar as possibilidades de identificação do patrimônio industrial, uma vez que se pode considerar que todo o território de influencia das organizações - sejam industriais, comerciais ou de serviços, sejam urbanas ou rurais - possui formas de expressão materiais e imateriais que remetem ao patrimônio industrial. Assim, devem ser consideradas as formas de expressão imateriais, como o savoir-faire, a evolução da técnica e da tecnologia que se baseiam em conhecimentos e se apresentam expressas de maneira não-material.

\section{Paisagem Cultural e Paisagem Industrial}

A paisagem cultural entendida como forma ampla de preservação da memória e da história encontra-se revestida de conceitos interdisciplinares. O espaço geográfico, a relação espaço-temporal, as mudanças sociais e as estruturas advindas das relações entre os elementos proporcionam um complexo entendimento das interações existentes. Dentre as ampliações ocorridas no conceito de patrimônio cultural inclui-se a que envolve a paisagem cultural proposta na Convenção da UNESCO em 1999, a partir do documento "Diretrizes Operacionais para a Implementação da Convenção de Patrimônio Mundial" que a define

[...] paisagens culturais representam o trabalho combinado da natureza e do homem designado no Artigo I da Convenção. Elas são ilustrativas da evolução da sociedade e dos assentamentos humanos ao longo do tempo, sob a influência das determinantes físicas e/ou oportunidades apresentadas por seu ambiente natural e das sucessivas forças sociais, econômicas e culturais, tanto internas, quanto externas (UNESCO, 1999).

Entretanto, o conceito pode ser percebido desde a Convenção de 1972 que definiu critérios para a proteção do patrimônio mundial cultural e natural que abrangem de maneira conjunto os conceitos que relacionam os elementos considerados para se definir paisagem cultural. Assim, o patrimônio cultural que envolve o conceito de paisagem cultural estaria relacionado àqueles conjuntos paisagísticos que envolvem elementos desenvolvidos pelo homem e que se caracterizem por certa relevância cultural e a paisagem natural. O patrimônio cultural que circunscreve o conceito de paisagem cultural envolve tanto componentes naturais como construídas, envolve os elementos naturais e os elementos arquitetônicos e arqueológicos.

Observa-se, ainda, o conceito proposto na Carta de Bagé ou Carta da Paisagem Cultural que define em seu Artigo $2^{\circ}$.

[...] A paisagem cultural é o meio natural ao qual o ser humano imprimiu as marcas de suas ações e formas de expressão, resultando em uma soma de todas os testemunhos resultantes da interação do homem com a natureza $e$, reciprocamente, da natureza com homem, passíveis de leituras espaciais e temporais (IPHAN, 2007, p.1). 
Faz-se referência à necessidade de se estabelecer e reconhecer a paisagem cultural como um elemento natural e construído em que se apresenta a necessidade de preservação e conservação cuja abrangência tem em seu Artigo 13:

[...] A paisagem cultural inclui, dentre outros, sítios de valor histórico, pré-histórico, étnico, geológico, paleontológico, científico, artístico, literário, mítico, esotérico, legendário, industrial, simbólico, pareidólico, turístico, econômico, religioso, de migração e de fronteira, bem como áreas contíguas, envoltórias ou associadas a um meio urbano (IPHAN, 2007, p.3).

Complementada por Tuan (1975), a paisagem cultural considera ainda as relações existentes entre paisagem e lugar em que se tem a primeira como representação de diversas percepções que se altera a partir das diferentes maneiras como é interpretada. O lugar tem em sua definição uma perspectiva de existência estável que está relacionada às experiências, individuais ou coletivas, nele ocorridas e que compreendem e é compreendido, necessariamente, a partir do "olhar" do outro.

Nesse sentido e se considerando os componentes construídos e/ou modificados pelo homem, deve-se dar relevância à vida social, às construções e ao desenvolvimento urbano das cidades e da sociedade que não podem ser vistos de maneira independente e desconectados. As diferentes relações que se estabelece entre sociedade e organizações (ou pode-se dizer empresas) determinam perspectivas particulares para a construção de conceitos de patrimônio e cultura que extrapolam os aspectos comumente abordados.

Sob essa perspectiva, a memória e a cultura social se compõem de um imaginário que se relaciona à percepção dos grupos sociais e dos indivíduos que se identificam segundo determinadas perspectivas envolvendo, inclusive, o campo do trabalho. A construção do eu (indivíduo) e do social (grupos, comunidade) decorre, assim, de experiências vividas que incluem aquelas ocorridas no âmbito do trabalho e das organizações e por eles determinadas.

A representação e inclusão de conjuntos industriais relacionados pela UNESCO como patrimônio cultural pode-se considerar e classsificá-los como paisagem cultural. Dentre aqueles inclusos na lista, tem-se os casos apresentados por Rufinoni (2009), que considera

[...] os sítios industriais no reino Unido (Blaenavon, saltaire e New lanark, bem como os Moinhos do vale de Derwent e a paisagem mineira da Cornuáliae do oeste de Devon, entre Reino Unido e Irlanda do Norte); na Alemanha (usina siderúrgica de Volklingen, e o complexo industrial da Mina Carvoeira de Zollverein); na Suécia (as forjas de Engelsberg e a área mineira daGrande Montanha de Cobre em Falun), na Itália (sítio industrial Crespi d'Adda); no Chile (usinas de salitre de Humberstone e Santa Laura e a cidade mineira de Sewell); assim como áreas de exploração e produção em vários países e certas estruturas industriais significativas como o conjunto de elevadores do Canal du Centre, na Bélgica (RUFINONI, 2009, p.154). 
Apesar da ampliação das percepções e dos exemplos anteriormente apresentados, deve-se considerar que atualmente, segundo Araújo (2009), a análise e interpretação dos conjuntos considerados patrimônios culturais, no Brasil, encontrase determinada por parâmetros tradicionais e somente permitirá mudanças e ampliação se houver uma atuação compartilhada entre os diversos indivíduos e grupos envolvidos, além de uma capacidade de construção de identidade e

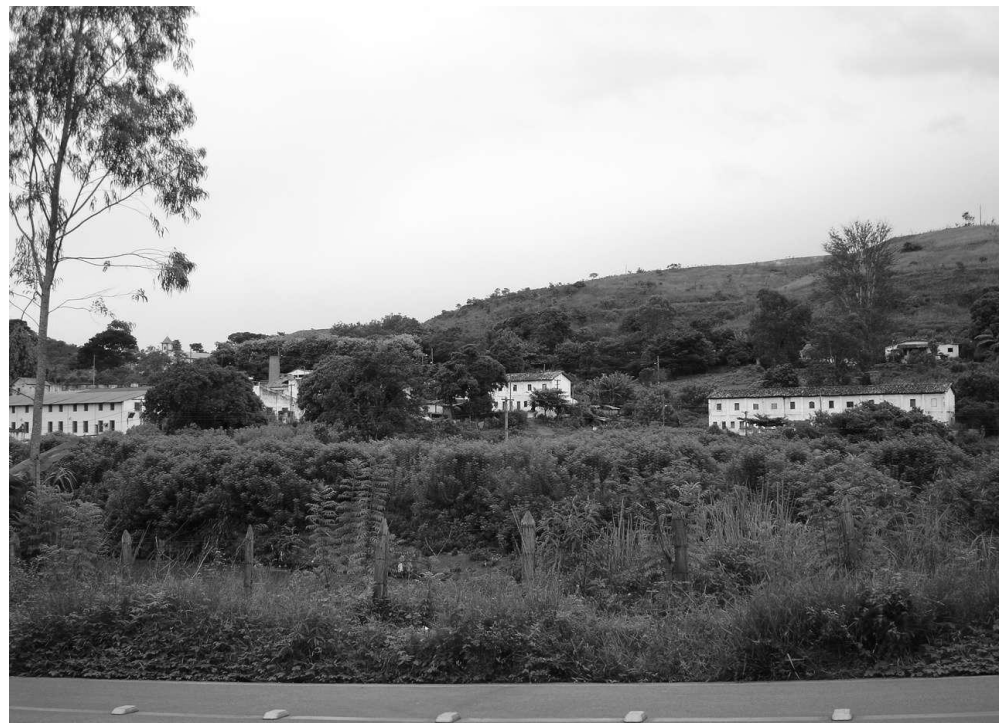

Figura 02. Conjunto Arquitetônico e Paisagístico: Vila Elisa, Vila Operária e Antiga Fábrica de Tecidos de Marzagão - Sabará [MG], Brasil. Fonte: IEPHA [MG], <www.iepha.mg.gov.br>, 2008.

identificação das paisagens culturais pelas populações de seu entorno.

Complementarmente, para um entendimento global da paisagem cultural, torna-se necessário compreender o conceito de paisagem cultural conjuntamente àquele relacionado à arqueologia da paisagem. Tem -se que as linhas de atuação da arqueologia da paisagem permeiam e arqueologia da arquitetura e permitem a construção de contribuições destinadas ao entendimento das atividades arqueológicas em sítios que determinem uma maior capacidade de reconstituição dos espaços utilizados, bem como aspectos sócio-culturais que dele derivam. Alguns aspectos considerados na arqueologia da paisagem ligados à paisagem cultural são essenciais para se entender a interrelação existente. A arqueologia preventiva, segundo Morais (2007), se define como

[...] o processo de artificialização do meio, na perspectiva dos sistemas regionais de povoamento. Seu tema central é a reconstrução dos cenários das ocupações humanas, com foco na dispersão das populações pelo ecúmeno, episódio que gerou paisagens específicas [...] a arqueologia da paisagem converge seus esforços em duas dimensões: a matriz ambiental natural, relacionada com o meio físico-biótico, e o ambiente modificado, relacionado com o meio socioeconômico e cultural [...] o estudo dos processos sociais em sua dimensão espacial, reconstruindo e interpretando a evolução da paisagem arqueológica e os padrões de assentamento a partir das expressões materiais da cultura (MORAIS, 2007, p.103).

Dessa maneira, pode-se perceber a utilização de uma abordagem interdisciplinar que torna possível um amplo entendimento dos conceitos relacionados à paisagem cultural. $\mathrm{O}$ auxilio de tecnologias e de processos adequados permite análises de áreas de interesse e de maneira integrativa. Uma atuação integrada possibilita o desenvolvimento de conhecimentos e envolve uma dinâmica de (re)construção ou (re)definição das formas de atuação de diversos grupos e/ou indivíduos envolvidos a fim de determinar novas formas de pensar a paisagem cultural. 
A paisagem cultural, segundo as múltiplas dimensões assumidas pelo conceito atualmente proposto e conforme apresenta Fowler citado por Castriota (2009a), permite uma multiplicidade de interpretacoes que necessitam uma análise ampla e perspectivas de atuação multidisciplinares que privilegiem os mais diversos aspectos, bem como uma capacidade de interação entre os âmbitos natural e cultural, material e imaterial que, por muitas vezes, apresentam-se ignorados.

\section{Paisagem Cultural Industrial Brasileira}

O caso brasileiro apresenta uma perspectiva do binômio empresa-sociedade associada, principalmente, às empresas pioneiras nas diversas regiões do Brasil a partir dos processos de proto-industrialização, final dos séculos XVIII e início do século XIX, principalmente com o Ciclos da Cana de Açúcar e do Ouro, e de industrialização, seja em um período mais remoto - final do século XIX ou inicio do século XX - ou mesmo mais próximo. Deve-se considerar que as organizações produtivas, em alguns casos, contribuíram e contribuem para o desenvolvimento local, não somente sob o papel do capital, mas também sob a égide do social.

O desenvolvimento dessa centralidade tem influência na formação e desenvolvimento de cidades e se torna um dos fatores de aglutinação social e de formação cultural dos centros urbanos e rurais em que se estabeleciam relações empresa-comunidade. A busca por um compartilhamento das necessidades sociais entre empregados e empresa determina peculiaridades nas relações estabelecidas e particularidades em relação às organizações que se estabeleceram por meio de frutos sociais de suas atividades: a criação de vilas operarias, centros de lazer (cinemas, teatros, rádios, clubes esportivos etc) e outras atividades sociais constituídas por funcionários e suas famílias. A partir da implantação e da adequação de experiências, muitas delas inglesas, de vilas operárias, se estabelecem experiências brasileiras em diversos ramos, como o das monoculturas canavieira e cafeeira no Brasil, ou as indústrias têxteis. A partir delas surgem as primeiras formações de conglomerados sociais, como as apresentadas por Correia (2001), sob diversas denominações'.

A constituição das organizações e suas componentes sociais, tais como as vilas operárias, tem seus primórdios nas empresas têxteis inglesas estabelecidas nos séculos XVII e XVIII nos quais se desenvolveu a Revolução Industrial e o espírito capitalista. A partir destas experiências tem-se que as empresas se constituíram em pólos de desenvolvimento não somente econômicos, mas também urbanos e de formação de cidades.

Segundo Kohlsdorf (1996), os modelos de cidades-indústria desenvolvidos no século XIX foram desenvolvidos a partir das propostas apresentadas por Owen, Fourier e Godin, principalmente pelo primeiro através da cidade-fábrica New Lanark. Após a implementação e sucesso destes modelos, tidos como desenvolvimentistas e

\footnotetext{
1 Dentre as denominações utilizadas para esta integração entre empresa e sociedade tem-se vila operária, fazenda, usina, bairro proletário, núcleo urbano, núcleo industrial, núcleo residencial, núcleo fabril, cidade operária, cidade-companhia, cidadeempresa e cidade nova.
} 
progressistas, elas se espalharam pelo continente americano, principalmente na Nova Inglaterra com as cidades-moinho. No principio do século $X X$, tem-se como principais exemplos, a Cité Industrielle de Tony Garnier anunciou os CIAMs, a Carta de Atenas e a cidade funcionalista, delineando um modelo urbanístico progressista para as cidades soviéticas e algumas cidades-industriais alemãs - por exemplo, Salzgitter.

Uma afirmação complementar de Pereira (1993) apresenta a necessidade de se desenvolver vilas operárias no entorno das empresas ou empreendimentos realizados ao final do século XIX e início do século XX, na Europa, e que se reflete também no Brasil e que está ligada ao fenômeno das concentrações populacionais estabelecidas pelo fenômeno urbano mesclado à implantação de indústrias e/ou monoculturas agropastoris.

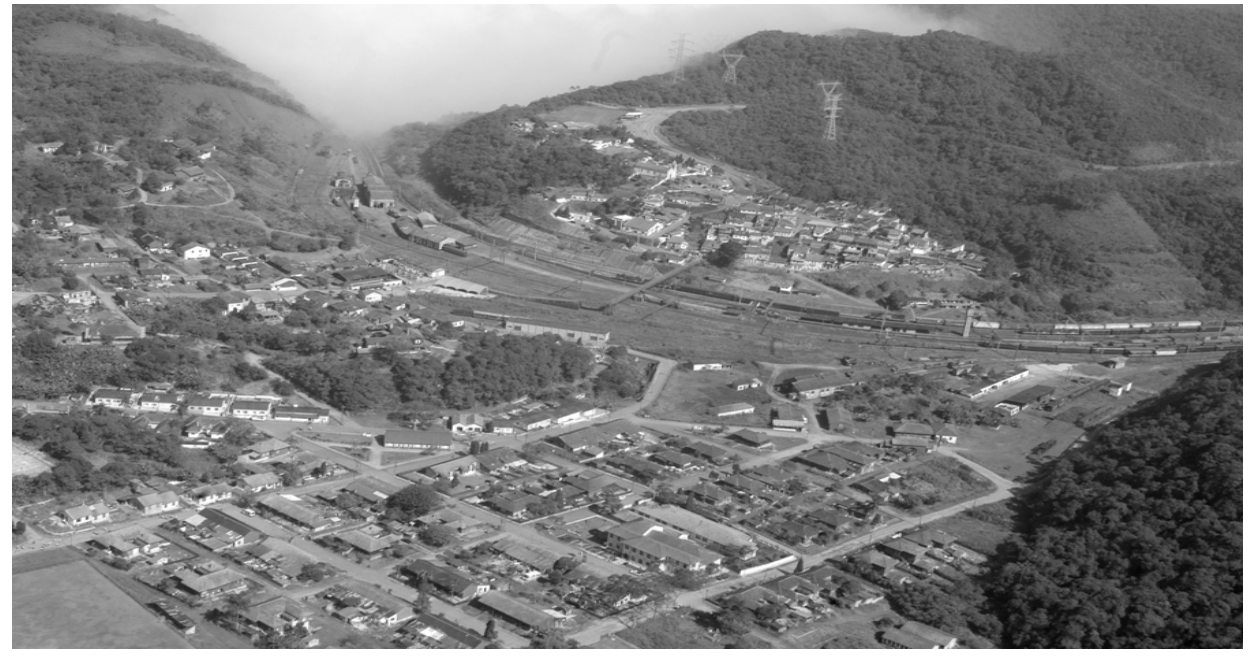

Figura 03. Vila Ferroviária de Paranapiacaba. Santo André [SP], Brasil. Fonte: Júlio Bastos, Prefeitura Municipal de Santo André, [s/d].

Para Herédia (2003), a criação da vila operária, nos casos brasileiros, interliga-se à necessidade de fixação da força de trabalho próxima à fábrica, que além de garantir uma maior capacidade de controle dos mesmos. Assim, o desenvolvimento das mesmas com habitações, escola, armazém, cooperativa, auxílio mútuo e associação beneficente, possibilita a manutenção da força de trabalho familiar e garante a reprodução da mão-de-obra necessária à organização. Os espaços sociais definidos pela organização são transformados em lugares de memória, denominação dada por Nora (1997) aos pontos de referência com que se trabalha a memória e não simplesmente aos pontos de referência construídos a partir de lembranças.

Devem ainda ser considerados os aspectos relacionados à empresa que contribuem para a formação das comunidades - rurais e urbanas - e que tem certa relevância nas mudanças ocorridas na vida social, cultural e do trabalho de determinados grupos. Estas influências estão presentes no que se pode denominar como "equipamentos comunitários" ou "equipamentos coletivos urbanos" (TOPALOV, 1990), "condições gerais de produção" (LOJKINE, 1988) o "meio ambiente construído" (HARVEY, 1989) que envolvem não somente o âmbito empresarial ou industrial, mas também as residências, comércio, escolas, hospitais, áreas de lazer e estrutura de serviços urbanos (água, energia, telefonia etc.). 
Tem, com isso, que a memória empresarial traz consigo um sem número de recordações que são parte de seu passado e que compreendem a história das pessoas que fazem e fizeram parte dela. Além disso, a empresa provoca e sofre mudanças em função de seu entorno que se constrói a partir dos fatos e feitos sócioeconômicos e culturais. Sob essa perspectiva, percebe-se a pertinência em se transformar o saber construído na empresa y em seu redor. A importância destas mudanças encontra-se em se tornar possível a preservação dessa memória como fator essencial para se entender as contribuções pessoais e sociais da empresa na e para a sociedade (WORCMAN, 1999, 2004).

\section{Memória Cultural e Memória Industrial}

A conceitualização de memória apresenta variáveis que se entrecruzam e garantem uma condição de transdisciplinariedade relacional entre o existente no presente e que pertence ao passado. Estabelecer relações entre memória e identidade e, consequentemente, entre memória social e memória coletiva representa construir uma análise dos quadros da representação e da memória coletiva nos quais se pode verificar a amplitude das relações estabelecidas nas interações sociais (SANTOS, 1998).

Dentre as questões relacionadas à memória, sua construção e relações com as identidades individuais e sociais que se apropriavam delas têm-se estudos complementares à introdução do conceito de memória coletiva apresentados por Aguilar Mejía e Quintero Álvarez (2005) que citam o trabalho de Olick e Robbins (1998) e determinam o princípio do fenômeno de memória coletiva aos escritos de Hugo von Hofmannsthal em 1902. Além disso, a importância dos estudos de Halbwachs realizados nos anos 20 do século XX são pontos importantes para descrever o fenômeno.

O conceito construído por Halbwachs de memória coletiva apresentado por Ángel Aguilar (1991), fundamenta-se na construção no presente de fatos passados os quais trazem significados para um determinado e específico grupo. Estas recordações têm significados próprios que garantem certos graus de importância com relação à construção de identificação e identidade. Geralmente se estabelece segundo mudanças e transformações que se constituíram em um tempo e espaço de vida específicos das pessoas ou grupos a que pertencem. Para isso, os indivíduos e grupos têm

[...] necessidade de reconstruir e inventar o passado enquanto haja mister. Os grupos têm necessidade de reconstruir permanentemente suas recordações através de suas conversas, contatos, rememorações, efemérides, uso e costumes, conservação de seus objetos e pertences e permanência nos lugares onde haja desenvolvido sua vida, porque a memória é a única garantia de que o grupo segue sendo o mesmo, em meio a um mundo em perpétuo movimento (ÁNGEL AGUILAR, p.2).

Assim, a memória assume um caráter de comunicação, diferentemente da história que tem um caráter de informação. A primeira está relacionada às recordações 
estabelecidas pelos indivíduos que expressam os fatos e fenômenos passados a partir de suas experiências pessoais. A intenção não compreende em fazer presente os fatos e as experiências, mas sim recordá-las ainda que não hajam existido como experiências próprias, pois são consideradas recordações que se fazem presentes a partir do conceito da comunicação.

Os processos de comunicação podem, assim, ser definidos como fatores de interpretação e criação dos espaços de pertinência social, enquanto as linhas de comunicação acontecem de maneira atemporal por se desenvolverem segundo a capacidade de organização e das relações espaço-tempo definidas como importantes pelos grupos sociais. Entretanto, o conceito da palavra memória está intimamente relacionado ao conceito de história e Halbwachs (1990) distingue dois tipos específicos de memória que seriam: a memória pessoal e a memória social. A primeira também pode ser chamada de autobiográfica e a segunda de memória histórica. Assim, torna-se importante perceber que a segunda é mais ampla e geral e traz consigo os conceitos da primeira porque a historia de vida das pessoas faz parte do todo que seria a história do coletivo.

As conexões entre indivíduo e coletividade têm sido definidas a partir das relações a eles inerentes, não se podendo esquecer que os signos e símbolos definidos na memória coletiva determinam os marcos principais da vida social. Eles necessitam ter significado às pessoas, pois a identificação e a identidade que elas percebidas em relação a estes pode garantir a perpetuação da memória coletiva. Ainda assim, para a construção da memória na vida pessoal ou social torna-se necessário estabelecer e identificar dois importantes fatores: o tempo e o espaço. O primeiro se relaciona às datas e fenômenos que fazem parte da memória coletiva. Eles são pontos de referência e têm um significado especial aos indivíduos que com eles se identificam e trazem certa identidade; o segundo está estabelecido de maneira mais real e absoluta, através das edificações, espaços de convivência, de ócio, de trabalho e nos quais se estabeleceram as recordações pessoais e/ou grupais.

A separação ou relação entre tempo e espaço define a construção de processos de interação e interrelação entre os dois fatores e cuja determinação de graus de pertinência, importância e recordações estão definidas a partir da interpretação do tempo segundo o impacto das distâncias (geográficas) ou a dimensão dos espaços locais. Esta capacidade de inclusão ou exclusão do indivíduo ou grupos nos espaços e segundo uma determinada época permite a construção da memória e a definição dos fatores considerados importantes. Assim, a definição de tempo, na atualidade, não se faz em função dos espaços e, sim, se impõe como fator definidor dos processos e lugares pessoais e sociais. A coordenação cronométrica entre indivíduos e os diferentes lugares permite a criação das articulações entre fatos e recordações. A rearticulação das regiões espaço-temporais não territoriais (a memória) e os meios e fatores definidos como unidades simbólicas de presença e pertinência definem sistemas abstratos organizacionais (a cultura) e a capacidade de reflexividade destes nos indivíduos e grupos.

Para Melucci (1989), as relações entre espaço-território e espaço físico estão determinadas, de maneira geral, pelo que se considerava perto nas sociedades prémodernas. Os lugares ou espaços de pertinência e identidade mudam e deixam de 
ser pontos de subsistência básica, segundo o entorno de confiança definido pelos indivíduos ou grupos, sendo, assim, definidos pelos entornos nos quais a configuração humana constrói suas relações de integração não necessariamente presencial. Pois a memória tem como uma de suas características a presença de fatos e fenômenos passados no presente, a atemporalidade. Mas, ela, também, se faz dinâmica e sistêmica sendo construída segundo os espaços abertos e com relação à exterioridade e outros grupos/atores sociais.

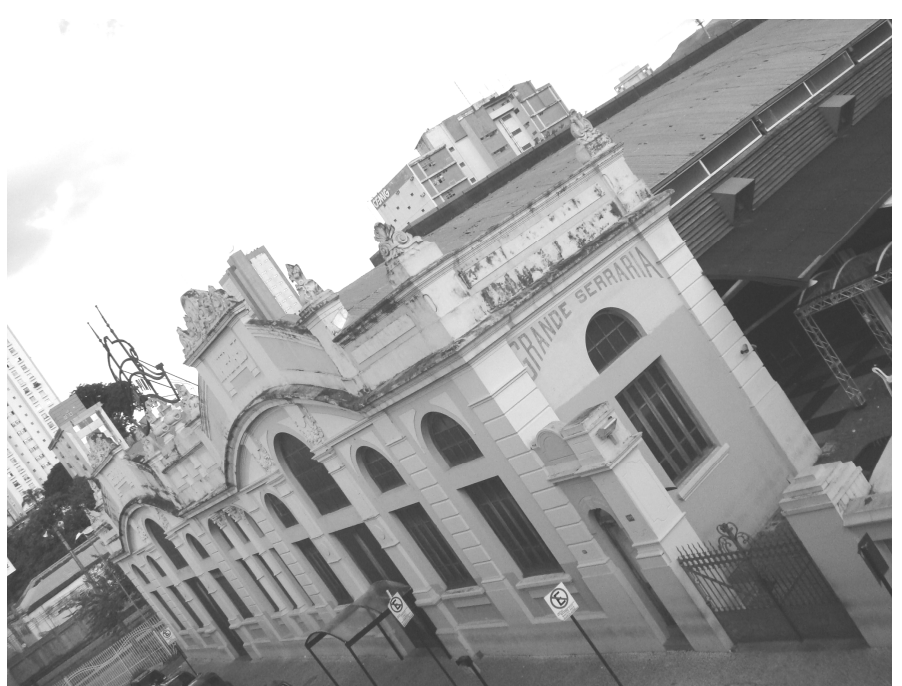

Figura 04. Serraria Souza Pinto - Belo Horizonte [MG], Brasil. Fonte: Ronaldo Rodrigues, 2010.
As possibilidades de construir relações entre passado, presente e futuro também se determinam pela necessidade humana de construir a memória. As práticas que definem sua construção estão delineadas a partir de conceitos que apontam para fatores multidisciplinares - míticos, históricos, políticos etc. - que permitem a construção e reconstrução das bases das relações pessoais e sociais. Estas referências permitem ao homem e à sociedade uma estabilidade do imaginário construído e real e garante a identificação e a

identidade individual e coletiva aos diversos grupos sociais (FERREIRA e ORRICO, 2002).

Assim, o processo espaço-tempo se expande e se produz segundo as mudanças e as interpretações feitas pelas pessoas e os grupos. Dentre as condições que facilitam esta identificação e identidade com relação à variável espaço-tempo tem-se a contextualidade e a funcionalidade que determinam estas mudanças que se relacionam à percepção do passado, a partir das relações baseadas na integração primária e co-presencial. Muitas vezes, as maneiras de se perceber o passado advêm de experiências próprias que determinam as principais recordações. Mas, a integração sistêmica e, principalmente a integração social, organiza-se ou se estabelece segundo as estruturas e relações sociais a partir da ordem de importância dos fatos sociais, da proximidade e da imediaticidade que também podem ser consideradas como pontos de definição da memória pessoal e social.

Nos últimos 20 anos as preocupações com a relação espaço-tempo estão centradas no contexto constantes mudanças dos processos sociais. A idéia de temporalidade associada às mudanças sociais tende a redefinir o processo industrial segundo um "mimetismo histórico" no qual se tem a adaptação das bases do capital aos processos específicos que lhes corresponde e lhes determina. As novas regras do mundo sociológico segundo os contextos de espaço-tempo definem um distanciamento e se reorganizam para adequarem-se às mudanças sociais e à construção e reconstrução da estratificação social, e suas mais diversas formas de associação (MELUCCI, 1989; CASTELLS, 1998, 1999). 
Enquanto determinam o comportamento dos indivíduos e seus grupos de pertinência, os fatos passados constituem marcos importantes para a construção do presente e para a redefinição daquilo considerado importante ou não para o homem e a sociedade. Esta identificação e relação entre passado e presente e suas implicações podem ser interpretadas segundo a idéia de "compressão espaço temporal" de Harvey (1989). Tal significado pressupõe que os fatos e a vida presente estão baseados na história de vida pessoal e coletiva a partir das quais se constrói e se interpreta aquilo que é importante e se determinam as relações pessoais e sociais.

Assim, se pode avaliar as compreensões e interpretações que fazem as pessoas e os grupos dos fatos e fenômenos que ocorrem ao seu redor. Esta relação entre fatos e interpretações e a importância ou não dada a eles pela sociedade e indivíduos tem o significado que, para Lash e Urry (1994), são pressupostos de uma nova economia de signos e espaços. Os lugares da memória passam não somente a serem referências de um passado pessoal ou social, mas também significam, justificam e caracterizam as formas de interpretação de tempo presente (AUGÉ, 1989).

Estas perspectivas de desenvolvimento e entendimento do passado a partir das relaciones entre fatos e fenômenos e sua simbologia apresentam perspectivas diferenciadas nos mais diversos âmbitos - cultural, econômico, gênero, comunidades etc. - pois apresentam o espaço como um dos objetivos e eixos no estudo do tempo.

A necessidade de uma construção histórica e de criação da memória a partir do "materialismo histórico-geográfico" de Soja (1996) ou dos fluxos de espaço/tempo de Castells (1997) possibilitam a recuperação da idéia de uma relação espaço/tempo na qual se cria uma perspectiva de simultaneidade e atualidade torna o tempo "atemporal". Além destes fatos, tem-se que a descontinuidade moderna também tem seus reflexos na construção da memória, pois ela está presente nos mais diversos âmbitos da vida humana: a interpretação dos fatos e a construção de estruturas tradicionais existentes (família, religião, grupos de pertinência etc.) e a determinação das estruturas simbólicas de pertinência (trabalho, economia, relações sociais, cultura etc.). As características de pertinência se constituem a partir da identificação e da identidade em relação aos grupos de integração, mas sofrem modificações dinâmicas que reafirmam a necessidade de reconstrução permanente. A integração social e sistêmica, além da ocupação e pertinência a distintos espaços individuais ou grupais leva à interconexão de diversos grupos e determina a formação das chamadas identidades múltiplas.

Ao se construir a memória a partir das variáveis definidas pelos espaços de pertencimento, identidade e identificação, os indivíduos ou grupos determinam e são determinados pelos fatos e fenômenos que se fazem representar em suas vidas. Estas referências constituem-se em fatores que determinam o comportamento e criam significados na vida das pessoas e seus grupos de pertinência. Através das estruturas (edificações, espaços de convivência, de ócio, de trabalho etc.) e espaços sociais nos quais se desenvolvem as atividades que se tem como base para estabelecer as recordações e construir a memória pessoal e/ou grupal. 


\section{A Memória Social e a Memória Industrial}

A vida social e as construções e desenvolvimentos da sociedade, em algumas cidades, muitas das vezes ocorrem em função do desenvolvimento não somente das relações sociais como também das relações comerciais e de mercado. A relação estreita que existe entre uma cidade e as organizações industriais (ou prestadoras de serviço) que nela se instalam têm profunda ligação com o desenvolvimento social da primeira em conjugação com o desenvolvimento econômico da segunda.

Esta relação de interdependência traz consigo uma confluência, e mesmo dissonâncias, de interesse entre o capital [a organização] e o social [a cidade]. Os interesses econômicos e comerciais sobressaem-se na maioria das vezes, com o capital desenvolvendo-se a partir da utilização da mão-de-obra existente na região em que se instala e utilizando-se da infra-estrutura local, ou mesmo regional ou nacional, com o objetivo restrito de lucro.

No entanto, em alguns casos, principalmente se observadas as empresas pioneiras no processo de industrialização do Brasil, seja em um período mais remoto - final do século $X I X$ ou inicio do século $X X$ - ou mesmo mais próximo, tem-se que as organizações, em alguns casos, contribuem para o desenvolvimento local, não somente sob o papel do capital, mas também sob a égide do social. Tal processo de instalação e desenvolvimento de setores produtivos seja industrial ou agropastoril ocorre no Brasil desde os séculos XVII e VIII com o desenvolvimento dos ciclos e da "indústria" da cana-de-açúcar, do ouro, do café e outros menores como do fumo e borracha.

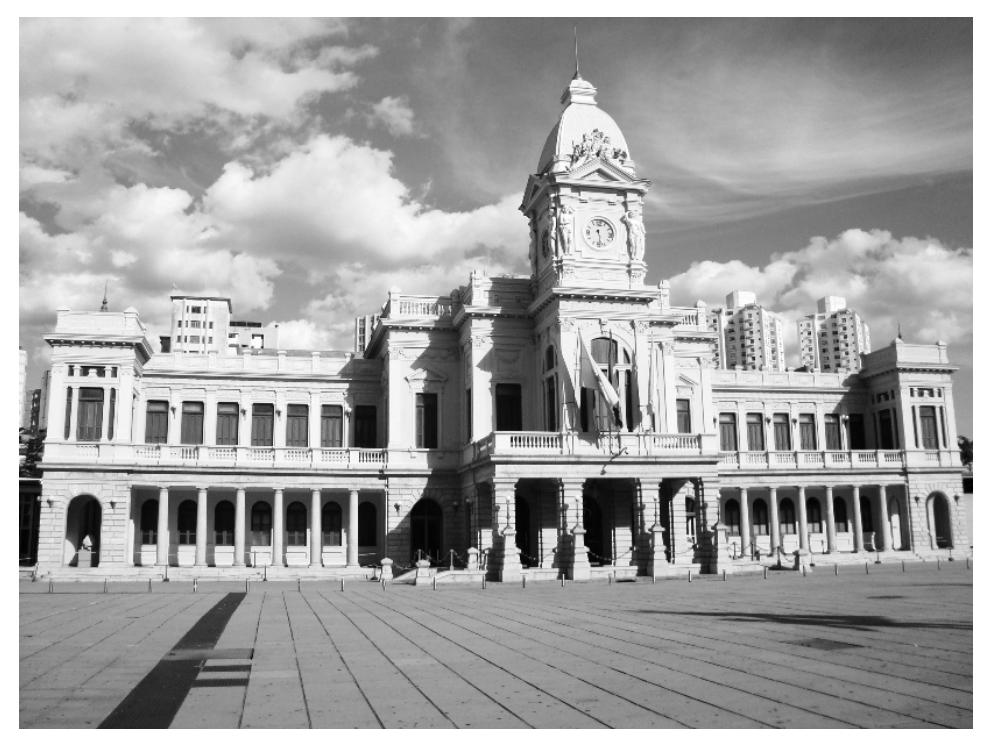

Figura 5. Estação Ferroviária - Belo Horizonte [MG], Brasil. Fonte: Ronaldo Rodrigues, 2010.
O desenvolvimento desta centralidade em torno das organizações tem influência na formação e desenvolvimento de cidades, sendo assim, um dos principais fatores de aglutinação social e mesmo de formação cultural dos centros em que se estabeleciam. A busca por um compartilhamento das necessidades sociais entre empregados e empresa determina uma peculiaridade nas relações estabelecidas. Nelas se têm particularidades em relação às organizações que não estabeleceram, como

fruto de suas atividades, a criação de vilas operarias ou quaisquer aglomerados sociais constituídos de funcionários e suas famílias (KELLER, 1998). 
Os sinais de paternalismo e de certo controle social dele advindos constituem-se fatores importantes para o estabelecimento das relações existentes entre empresa e sociedade. Tais aspectos são determinantes às atividades desenvolvidas tanto no âmbito organizacional quanto social e garantem a legitimidade e a interdependência necessárias para sua aceitação. O desenvolvimento das cidades, em alguns casos, com a implantação de indústrias determinou o crescimento e a acelerada urbanização das mesmas. Em alguns estudos, como os de Giroletti (2002) e Menezes (2003), apresentam as influências determinantes que foram estabelecidas nas relações sociais entre organização e sociedade.

Entretanto, os processos de articulação, e mesmo desarticulação, existente entre as políticas públicas dos Governos Federal e Estaduais, e antes Imperial e Províncias, determinou ao desenvolvimento industrial e econômico nacional e regional algumas diferenciações e convergências. Esta determinação histórica e a necessidade sócioeconômica em função de suas principais variáveis levaram ao desenvolvimento nãolinear do setor no Brasil. A influencia de crises e reajustamentos econômicos, os movimentos das classes sociais e suas inter-relações são fatores importantes que considerados permitem um esboço da trajetória do desenvolvimento setorial. (DULCI, 1999). Assim, o modelo industrial brasileiro se desenvolve a partir dos investimentos no Brasil Império e de três momentos chave do século XX: o processo de substituições das importações na década de 30, no período getulista; se incrementa consideravelmente na década de 50, período desenvolvimentista de Juscelino Kubitscheck; e estabelece-se finalmente na década de $90 \mathrm{com}$ a abertura do mercado brasileiro ao modelo liberal internacional e influências dos processos de globalização. Nos primeiros períodos, Prado Júnior (1972) e Furtado (2000) apresentam as desigualdades e diferenças de desenvolvimento decorrentes da industrialização nacional. Sua complexidade e abrangência, para os pensadores, encontram um caminho tortuoso e inconclusivo.

Para entender os processos de industrialização torna-se necessário observá-los sob as perspectivas social e econômica. As influências mútuas sofridas por estas configurações e seus aspetos reflexivos nas organizações responsáveis pelo desenvolvimento industrial mineiro e brasileiro podem ser entendidas a partir da preservação do patrimônio e do entendimento global da inserção da arqueologia industrial na história regional e brasileira. A reconstrução das mudanças sociais e dos processos econômicos regionais e nacional ocorrem assim, através de mudanças de foco empresariais, trazidas por empresários e engenheiros recémformados das escolas européias e nacionais (por exemplo, a Escola de Minas de Ouro Preto).

Eles propõem transformações sociais que delimitam o desenvolvimento e a evolução histórica do setor empresarial e da indústria brasileira. Esta pode ser entendida a partir dos investimentos, e desinvestimentos, realizados ao longo do período - final do século XIX e início do século XX - nos diversos setores. Tais variações podem ser interpretadas a partir da necessidade, do interesse e de tendências macrosociais que levaram à ascensão ou não de empresas e indústrias especificas ao longo dos séculos XIX e XX. (SUZIGAN, 2000; LIBBY, 1984, 1988). 
Para Dulci (1999), deve-se

observar que os desdobramentos advindos dos processos de

industrialização não se limitam às questões econômicomercadológicas, mas também influenciam e sofrem influências de determinações políticas, sociais e culturais. A memória industrial torna-se, assim, fator determinante para 0 entendimento da memória cultural na qual se tem os fatores materiais (as empresas em si) e imateriais (as memórias dos trabalhadores), tangível

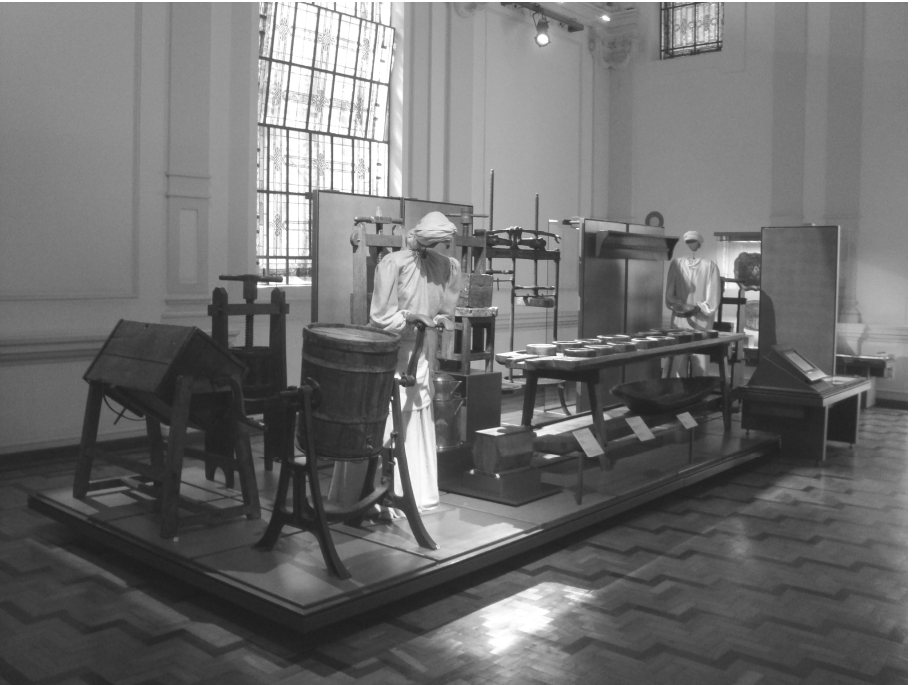

Figura 06. Museu de Artes e Ofícios - Belo Horizonte [MG],Brasil. Fonte: Ronaldo Rodrigues, 2010. (maquinários e tecnologia) e intangível (know-how e savoir faire).

\section{O Patrimônio Industrial: paisagem, memória e cultura}

Uma narrativa que se compõe da importância econômica-social da organização leva ao resgate de uma memória não somente da empresa como também da sociedade, que vai além das atividades produtivas e dos processos, produtos e serviços oferecidos. Os reflexos sociais da organização estão impregnados em várias ações da comunidade e em vários espaços da sociedade de seu entorno. Várias das características da cultura organizacional podem ser percebidas segundo suas interações com diversos grupos sociais, além das características percebidas no processo de formação da sociedade que ocorre segundo seu próprio desenvolvimento.

Assim, ao se estabelecer uma relação cultural e patrimonial entre organização e sociedade, faz-se necessário também construir as bases para as análises desta situação. As experiências observadas entre empresa e sociedade, segundo Thompson (1988), se desenvolvem a partir da percepção de ambos das necessidades sociais que podem ser preenchidas por essa relação. Elas são descritas como espaços em que a organização, através da criação das vilas operárias, se permite estar onipresente em diversas situações do cotidiano humano.

Desta forma, se constrói e se determina um imaginário social no qual se tem uma experimentação e formação do inconsciente a partir de elementos da cultura social, da vida cotidiana e das necessidades do homem. Tal interligação de necessidades e de pressupostos à vida social e à construção da comunidade permite uma satisfação das necessidades profissionais e coletivas, da organização e do social, do capital e do trabalho, além de formar e desenvolver uma inter-relação e interdependência entre eles. 
A construção de uma relação sociedade-empresa permite, segundo De Biase (1997), a afirmação de uma identidade na qual se tem traduzido para um espaço público (o social) todas as características e determinações de um espaço privado (a organização). As diversas formas e representações ideológicas passam a ser fatores de construção de um mundo social que se identifica não somente com características e culturas locais e regionais, como também com a formação social oferecida por uma entidade (a organização) específica.

A identificação dos pontos de referencia social e o seu reconhecimento como fatores de construção de uma vida privada e publica dos indivíduos, chamados por Palumbo (2000) de "objetos-sinais", permite a criação de uma identidade entre homem-objeto que lhe permite dar o sentido de pertinência ou pertencimento a partir de determinados elementos. Esta materialização do processo de criação de uma interrelação faz com que se construam referências que permitem desenvolver o conceito de patrimônio e de estabelecer marcos espaciais e temporais que garantem uma continuidade histórica.

\section{Reflexões culturais e patrimoniais}

A paisagem cultural, muitas vezes, relaciona-se à vida profissional e ao período econômico ativo de um indivíduo. A formação do homem e de suas relações sociais está impregnada de relações do trabalho que se compõem de diversos espaços diferenciados do "espaço fabril". A necessidade em se considerar o contexto sóciohistórico que envolve o entorno organizacional e principalmente o espaço social deve estar centrada na importância para a construção e desenvolvimento de uma identidade individual e coletiva acerca da memória e da cultura proporcionadas por um espaço específico.

Deve-se ressaltar que tais preocupações não vêm acompanhadas de igual relevância de estudos que considerem os aspectos e as variáveis humanas e sociais implicadas no processo de construção da história industrial. Os exemplos relacionados ao patrimônio industrial poderiam, além de ocorrer em maior número, significar um resgate e uma preocupação com a memória e a preservação de um particular patrimônio cultural.

Consideram-se, ainda, as dificuldades em se identificar e reconhecer determinadas manifestações da cultura material como patrimônio. Muitas vezes, as condições necessárias para a reutilização e reabilitação de determinados elementos muitas vezes encontram dificuldades, pois contrapõem interesses econômicos e de expansão social que têm como principal característica o desenvolvimento econômico e social.

Choay (2001) apresenta como fatores considerados "proibitivos" aqueles relacionados aos custos de manutenção refuncionalização de determinados espaços industriais em função de suas particulares características. Muitas vezes, ao processo de transformação dos espaços descaracteriza-lhe de suas funções originais e não permite remitir ao seu passado quando dele não se tem 
conhecimento ou não se faz parte da memória e historia. E, ainda assim, quando, em alguns casos, se faz presente uma identidade ao passado, essa aparece relacionada, primeiramente, às possibilidades de valorização e integração à vida cotidiana pós-moderna, sem avaliar e considerar o caráter identitário do espaço considerado.

Essa capacidade de identificação entre sociedade-empresa, entre objeto-indivíduo, entre lugares-memória compreende também uma relação de simbolismo que Silveira e Lima Filho (2005) reconhecem como "a alma nas coisas". A identidade criada representa uma relacao existente entre algo imaterial (a memória) e sua transposição para objetos, coisas ou elementos materiais (patrimônio arquitetônico, urbano ou industrial). Tal capacidade de identificação entre homem e "objetos" cria possibilidades de desenvolver ações ou mesmo conscientizar outros indivíduos ou grupos sobre a importância destes "lugares" ou "objetos" para seu fortalecimento de sua própria identidade ou seu próprio "eu".

Ainda para Silveira e Lima Filho (2005) essa identidade também pode ser desenvolvida a partir da disciplina denominada antropologia do objeto documental que proporciona uma ampliação do entendimento das dinâmicas sociais que envolvem as relações do homem com o lugar [o espaço] além de criar uma relação destes com o tempo (a memória). Dessa maneira, a identificação do individuo ou grupo com relação à necessidade de se conhecer o passado recente da sociedade em que se vive permite desenvolver uma maior identidade e formação cultural sobre a cidade e o patrimônio nela contido.

A identiicação do patrimonio industrial como patrimonio cultural, além de permite construir uma visao diferenciada da paisagem industrial como paisagem cultural, permite a multiplicacao de olhares que necessitam do envolvimento de indivíduos e grupos com uma relação de identificação, de identidade e de desenvolvimento de uma cultura patrimonial industrial material/imaterial. A reconstrução da memória histórica através cultura material e da cultura industrial cria uma oportunidade de se desenvolver e incrementar uma identidade individual ou coletiva, além da social cujo patrimônio se constitui a partir de processos "industriais" relevantes à evolução das sociedades cujas implicações sócio-culturais surgidas refletem a relação empresasociedade.

Observar os entroncamentos e interconexões existentes entre os conceitos de patrimônio, cultura e indústria, entre a materialidade e o imaterial é um desafio à interdisciplinaridade do 'patrimônio cultural' amplo. A partir deles se tem uma ampliação do conceito que permite desenvolver a memória e a história culturais as quais possibilitam um maior entendimento da presença contínua entre passadopresente-futuro (BURITY, 2002). 


\section{Referências}

ABREU, Regina; CHAGAS, Mário (orgs.) Memória e patrimônio: ensaios contemporâneos. Rio de Janeiro: DP\&A, 2003.

AGUILAR MEJÍA, Oscar Mauricio; QUINTERO ÁLVAREZ, María Ximena. Memoria colectiva y organizaciones. Universitas Psychology, Bogotá, v. 4, n. 3, p. 285-296, 2005.

ÁNGEL AGUILAR, Miguel. Fragmentos de la memoria colectiva. Maurice Halbwachs. Revista de Cultura Psicológica, México: UNAM, año 1, número 1, 1991.

ARAÚJO, Guilherme Maciel. Paisagem cultural: um conceito inovador. In: CASTRIOTA, Leonardo Barci. Paisagem cultural e sustentabilidade. Belo Horizonte: IEDS; UFMG, p.25-45, 2009.

AUGÉ, Marc. La guerre des rêves, exercices d'ethno-fiction. Paris: Seuil, 1997.

BRASIL. Instituto do Patrimônio Histórico e Artístico Nacional. Patrimônio imaterial, Brasilia, 2003. Disponível em: <http://www.iphan.org.br>, Acesso em 12 jan. 2006, 00:12:44.

BRASIL. Instituto do Patrimônio Histórico e Artístico Nacional. Carta de Bagé, Brasilia, 2003. Disponível em: <http://www.iphan.org.br>, Acesso em: 28 jun., 2010.

BURITY, Joanildo A. (org.) Cultura e identidade: perspectivas interdisciplinares. Rio de Janeiro: DP\&A, 2002.

CASTELLS, Manuel. Identidad, estado, trabajo, tiempo y espacio en la sociedad red: contribución a un debate abierto. Revista Española de Investigaciones Sociológicas, Madrid: № 86, 1999.

La era de la información. Economía sociedad y cultura. El poder de la identidad. Madrid: Alianza Editorial, vol 2, 1998.

. CASTELLS, Manuel. Local y global. La gestión de las ciudades en la era de la información. Madrid: Taurus, 1997.

CASTRIOTA, Leonardo Barci. Paisagem cultural e sustentabilidade. Belo Horizonte: IEDS; UFMG, 2009a.

Leonardo Barci. Patrimônio cultural: conceitos, políticas, instrumentos. São Paulo: Annablume; Belo Horizonte: IEDS, 2009b.

CHOAY, Françoise. A alegoria do patrimônio. São Paulo: UNESP, 2001.

CORREIA, Telma de Barros. De vila operária a cidade-companhia: as aglomerações criadas por empresas no vocabulário especializado e vernacular. Revista Brasileira de Estudos Urbanos e Regionais, Recife, v. 4, p. 83-98, 2001.

DE BIASE, A. La creolizzazione dello spazio dove l'urbanistica non c'é. (Tesi di Laurea) - IUAV, Venezia, 1997.

DULCI, Otávio S. Política e recuperação econômica em Minas Gerais. Belo Horizonte: Ed. UFMG, 1999.

FERREIRA, Lúcia M.A.; ORRICO, Evelyn G.D. Prefácio. In: FERREIRA, Lúcia M.A.; ORRICO,Evelyn G.D. (orgs.). Linguagem, identidade e memória social. Rio de Janeiro: DP\&A, 7-12, 2002. 
FURTADO, Celso. Formação econômica do Brasil. São Paulo: Companhia Editora Nacional: Publifolha, 2000 (Grandes Nomes do Pensamento Brasileiro).

GALLO, Haroldo. Arqueologia, arquitetura e cidade: a preservação entre a identidade e a autenticidade. In: MORI, Victor Hugo et al. Patrimônio: atualizando o debate. São Paulo: IPHAN, p.91-116, 2006.

GIROLETTI, Domingos. Fábrica Convento Disciplina. Belo Horizonte: Imprensa Oficial, 1991.

HALBWACHS, Maurice. A memória coletiva. São Paulo: Vértica, 1990.

HARVEY, David. The condition of postmodernity. Cambridge: Basil Blackwell, 1989.

HERÉDIA, V. B. M. A construção se vilas operárias no sul do Brasil: o caso de Galópolis. Scripta Nova. Revista electrónica de geografía y ciencias sociales, Barcelona: Universidad de Barcelona, v. VII, n. 146(080), 2003.

HUDSON, Kenneth. Industrial archaeology. London: Methuen, University Paperbacks, 1965.

KELLER, Paulo. O cotidiano e o complexo. Revista REDES, Rio de Janeiro, v.2, n.6, set/dez., 1998.

KOHLSDORF, Maria Elaine. Ensaio sobre o pensamento urbanístico. Brasília: UnB, 1996.

LASH, Scott; URRY, John. Economics of signs \& space. Londres: Dage Publications, 1994.

LIBBY, Douglas Cole. Trabalho escravo e capital estrangeiro no Brasil: o caso de Morro Velho. Belo Horizonte: Itatiaia, 1984.

LIBBY, Douglas Cole. Transformação e trabalho em uma economia escravista: Minas Gerais no século XIX. São Paulo: Brasiliense, 1988.

LOJKINE, Jean. La clase obrera, hoy. México: Editorial Siglo XXI, 1988.

LÓPEZ GARCÍA, Mercedes. El concepto de patrimonio: el patrimonio industrial o la memoria del hogar. In: FERNANDEZ GARCÍA, Aladino; ÁLVAREZ ARECES, Miguel Ángel. (coords.) Arqueología Industrial (monográfico). Ábaco Revista de Cultura e Ciencias Sociales, Gijón: Nova Época, n.1, p.9-12, 1992.

MAGALHÃES, Aloísio. E Triunfo? A questão dos bens culturais no Brasil. Rio de Janeiro: Nova Fronteira / Fundação Roberto Marinho, 1997.

MELUCCI, Alberto Nomads of the present: social movements and individual needs in contemporary society. Philadelphia: Temple, 1989.

MENEZES, Lúcia Maria Pires. Juiz de Fora e a moradia popular: o Alto Santo Antônio. Scripta Nova, Barcelona: Universidad de Barcelona, vol. VII, n. 146(133), ago., 2003.

MINCHINTON, Walter. World industrial archaeology: a survey. World Archaeology, v.15, n. 2, p.125-136, oct., 1983.

MORAIS, José Luiz de. Arqueologia da paisagem como instrumento de gestão no licenciamento ambiental de atividades portuárias. Revista Eletrônica de Gestão de Negócios, eGesta, v.3, n.4, p.97-115, out./dez., 2007.

NORA, P. Lieux de mémoire. Paris: Gallimard, 1997. 
OLICK, Jeffrey K.; ROBBINS, Joyce. Social memory studies: from 'collective memory' to the historical sociology of mnemonic practices. Annual Review of Sociology, Palo Alto: v. 24, p. 105-140, 1998.

PALMER, Marilyn; NEAVERSON, Peter. Industrial archaeology: principles and practice. Londres: Routledge, 1998.

PALUMBO, B. Poétique de l'histoire et de l'identité dans une ville de la Sicile orientale. In: FABRE, D. (Org.). Domestiquer l'histoire: ethnologie des monuments historiques. Paris: De la Maison de Sciences de l'Homme, pp. 35-55, 2000.

PEREIRA, Nuno Teotónio. A promoção privada do alojamento operário, 1870/1930. In: Evolução das formas de habitação pluri-familiar na cidade de Lisboa. Lisboa: Fundação Calouste Gulbenkian, 1993.

PRADO JÚNIOR, Caio. História e desenvolvimento, 1aㅡ edição, São Paulo: Brasiliense, 1972.

RUFINONI, Manoela Rossinetti. Preservação e restauro urbano: teoria e prática de intervenção em sitios industriais de interesse cultural. (Tese de doutorado). São Paulo: FAU/USP, 2009.

SANTOS, Myrian Sepúlveda dos. Sobre a autonomia das novas identidades coletivas: alguns problemas teóricos. Revista Brasileira de Ciências Sociais, São Paulo: ANPOCS, v.13, n.38, 1998.

SILVEIRA, Flávio Leonel Abreu da; LIMA FILHO, Manuel Ferreira. Por uma antropologia do objeto documental: entre a "a alma nas coisas" e a coisificação do objeto. Horizontes Antropológicos, Porto Alegre, ano 11, n. 23, p. 37-50, 2005.

SOJA, E. W. Planning in for postmodernity. In: BENKO, Georges; STROHMAYER, Ulf (eds.), Space and social theory. Oxford: Blackwell, pp. 236-249, 1996.

SUZIGAN, Wilson. Indústria brasileira: origem e desenvolvimento. São Paulo: HUCITEC / Editora da Unicamp, 2000.

$\mathrm{TICCIH}$. The International Committee for the Conservation of the Industrial Heritage. Documentation, 2003. Disponível em: <http://www.mnactec.com/TICCIH>. Acesso em: 19 jan., 2004.

TOPALOV, Christian. La urbanizacion capitalista: algunos elementos para su analisis. México: Edicol, 1979.

TRINDER, Barrie. The blackwell encyclopaedia of industrial archaeology. Londres: Blackwell, 1992.

TUAN, Yi-Fu. Place: an experiential perspective. The Geographical Review, 65 (2), p.151-165, 1975.

WORCMAN, Karen. A história na empresa: identidades e oportunidades. In: Museu da Pessoa, São Paulo, 1999. <http://www. museudapessoa.com.br/biblioteca/pdfs/ahistorianaempresa.pdf>. Acesso em: 20 jan., 2006.

WORCMAN, Karen. Museu da pessoa: memória do futuro: um desafio. IN: NASSAR, P. (Org.). Memória de empresa: história e comunicação de mãos dadas, a construir o futuro das organizações. São Paulo: Aberje, 2004. p.23-30. 